\title{
LA METÁFORA DE LOS ANILLOS IMANTADOS Y LA INTERPRETACIÓN PLATÓNICA DE LA UNIDAD DEL ESTADO ${ }^{1}$
}

\author{
JAVIER AGUIRRE \\ Universidad del País Vasco
}

\begin{abstract}
RESUMEN: Tradicionalmente, la metáfora de los anillos imantados contenida en el monólogo socrático del lon se ha interpretado en clave epistemológica, en un contexto de debate sobre la naturaleza de la actividad poética. Sin negar este aspecto, la interpretación que se defiende en este artículo es que por medio de la metáfora de los anillos imantados se confrontan también dos modos opuestos de entender la unidad del Estado: una, la que se establece por medio de la téchne política, de naturaleza racional, autónoma, diferenciada y permanente; y otra, la de poetas y rapsodas, de naturaleza irracional, heterónoma, homogeneizadora y litúrgica.
\end{abstract}

PALABRAS CLAVE: Ion; República; Unidad del Estado; téchne; enthousiasmós.

\section{The metaphor of the magnetized rings and the Platonic interpretation of the State unity}

ABSTRACT: Traditionally, the metaphor of the magnetized rings contained in the Socratic monologue of platonic lon has been interpreted epistemologically, in a context of debate on the nature of the poetic activity. Without denying this aspect, the interpretation defended in this paper is that by means of the metaphor of magnetized rings are confronted two opposite ways of understanding the unity of the State: one, which is established by the political téchne, of a rational, autonomous, differentiated and permanent nature; and the other one, defended by poets and rhapsodists, of an irrational, heteronomous, homogenizing and liturgical nature.

KEY WORDS: Ion; Republic; Unity of the State; téchne; enthousiasmós.

\section{INTRODUCCIÓN}

Tradicionalmente, la metáfora de los anillos imantados contenida en el monólogo socrático del Ion se ha interpretado en clave epistemológica, en un contexto de debate sobre la naturaleza de la actividad poética a partir de la oposición entre la téchne y el enthousiasmós, es decir, entre el conocimiento sistemático y la inspiración divina ${ }^{2}$. De las tres partes en que cabe estructurar el breve diálogo platónico,

1 Este trabajo ha sido financiado por el proyecto de investigación «Los usos del humor en Platón. Ironía, humor y filosofía en los diálogos platónicos» del Programa Logos Fundación BBVA de Ayudas a la Investigación en el Área de Estudios Clásicos.

2 Toda la tradición erudita sitúa el diálogo en ese contexto, por otro lado, evidente. Durante el presente siglo se han publicado importantes monografías sobre el Ion: Pradeau (2001), Bremer (2005), Capuccino (2005), RiJKsBaron (2007) y AguirRe (2013). Todos ellos recogen la tradición y una extensa bibliografía sobre el diálogo y los temas y dificultades que plantea. 
en la primera y tercera se muestra que la actividad poética no es una téchne, en tanto que no satisface los principios de especialidad y de totalidad ${ }^{3}$, mientras que la segunda parte consiste en un monólogo en el que se muestra que la actividad poética es el resultado de la inspiración divina, de modo que la actividad del rapsoda (y del poeta) no responde a la posesión de un conocimiento sistemático, sino a un regalo divino de carácter temporal. En el monólogo central del diálogo Sócrates se vale de una metáfora según la cual la actividad de los poetas y rapsodas produce el mismo efecto que el que ejerce la piedra imantada sobre los anillos metálicos. Los dos pasos en que aparece la metáfora dicen así:

... Ion, voy a mostrarte lo que a mí me parece que es esto: en efecto, esto, hablar bien de Homero, no es un arte a tu alcance, como decía ahora mismo, sino una fuerza divina que te mueve, como en la piedra que Eurípides llamó magnética y la mayoría heraclea, pues también esta piedra no solo atrae los anillos de hierro, sino que infunde también una fuerza en su interior, de modo que ellos pueden ejercer eso mismo que la piedra, [533e] atraer otros anillos, de modo que, en algunas ocasiones, se forma una larga cadena de anillos de hierro que penden los unos de los otros; pero a todos ellos les viene de aquella piedra la fuerza que los sustenta. Del mismo modo, también la Musa, ella misma, crea inspirados, y por medio de estos inspirados se forma una cadena de otros que son presa de la inspiración. $(\text { Ion 533d-533e })^{4}$

Unos párrafos más adelante Sócrates continúa su exposición del siguiente modo:

¿Sabes, entonces, que éste, el espectador, es el último de los anillos de los que yo afirmaba que bajo la piedra heraclea adquieren la fuerza los unos de los otros? El del medio eres tú, [536a] el rapsoda y actor, y el primero es el poeta mismo. Y la divinidad, a través de todos ellos, atrae el alma de los hombres allí donde desea, haciendo depender la fuerza los unos de los otros. Y de igual modo que de aquella piedra, una cadena muy larga de coreutas, instructores y ayudantes de instructores están suspendidos de los anillos que cuelgan de las Musas. (Ion 535e-536a) ${ }^{5}$

3 Según el principio de especialidad, a cada téchne le corresponde uno y solo un dominio de objetos de conocimiento; según el principio de totalidad, la posesión de una determinada téchne conlleva el conocimiento experto sobre todos los casos que caen bajo el dominio de objetos del que se ocupa. En la primera parte del diálogo Sócrates trata de demostrar que la actividad poética no cumple el principio de totalidad, mientras que en la tercera trata de demostrar que la actividad poética tampoco cumple el principio de especialidad. Al negar que la actividad poética posea un objeto propio y un conocimiento sistemático sobre él, Sócrates está negando que la actividad poética constituya una téchne.

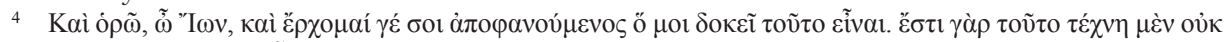

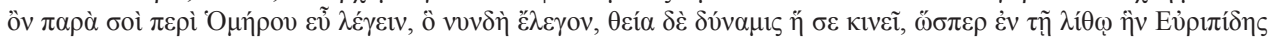

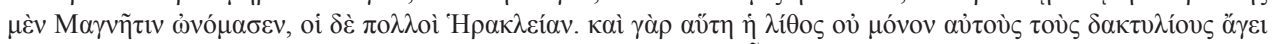

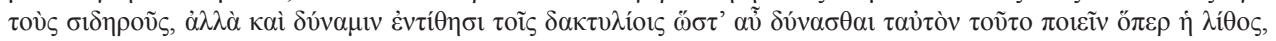

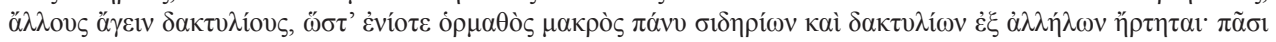

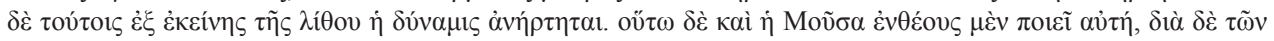

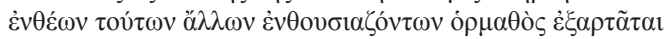

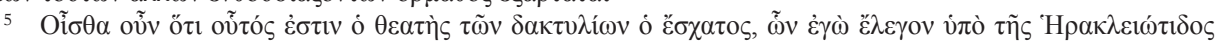

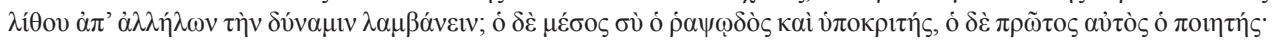

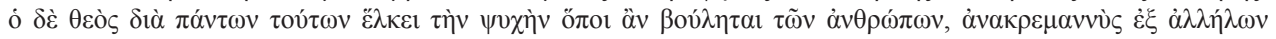

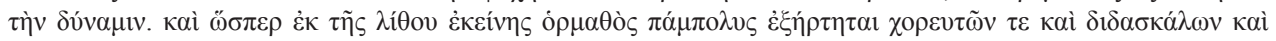

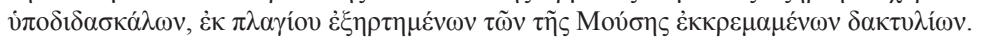


Sin negar la importancia que cabe atribuir a la evidente naturaleza epistemológica de la oposición establecida por Platón entre la actividad poética y las téchnai, habría que añadir que la interpretación epistemológica ha ocultado la lectura política que cabe hacer del monólogo en general y de la metáfora en particular. La interpretación que se defiende en este trabajo pone frente a frente no solamente dos modos de conocimiento, real uno, aparente el otro, sino también dos modos de entender la unidad de la polis y la cohesión social: una, la que se establece por medio de la poesía tradicional, caracterizada por su naturaleza irracional, heterónoma, homogeneizadora y litúrgica. Otra, la que se establece por medio de la téchne política, caracterizada por su naturaleza racional, autónoma, diferenciada y permanente. La unidad establecida por la dialéctica está profusamente descrita a lo largo de la República. La unidad poética está audazmente ilustrada mediante la metáfora de los anillos imantados. Veamos en qué consiste, a juicio de Platón, cada una de ellas.

\section{La REPÚBLICA: LA UNIDAD DE LA POLIS COMO BIEN SUPREMO}

La República contiene numerosos pasos en donde se señala que la unidad del Estado $^{6}$ constituye un bien supremo. Ello está claramente expuesto en el extenso diálogo entre Sócrates y Glaucón, donde leemos:

-Sócrates: «...nuestros gobernantes cuentan ya con el más acertado límite que deben fijar al tamaño del estado y del territorio al cual, de acuerdo con ese tamaño, han de delimitar, renunciando a cualquier otro». -Glaucón: «¿Cuál es ese límite?» —Sócrates: «...que el Estado esté en condiciones de crecer en tanto conserve su unidad, pero que no crezca más de allí...vigilar por todos los medios que el Estado no sea pequeño ni grande en apariencia, sino que sea uno y suficiente». (Rep. IV, 423b-c) ${ }^{7}$

Y más adelante, continúa el diálogo:

—Sócrates: «¿Y puede haber para un Estado un mal mayor que aquel que lo despedaza y lo convierte en múltiple en lugar de uno?»-Glaucón: «No puede haber un mal mayor». (Rep. V, 462a-b) ${ }^{8}$

Hay que subrayar, no obstante, que el bien supremo al que se refieren no se identifica con cualquier clase de unidad, sino con una unidad que cumple una serie de condiciones fundamentales. En efecto, una vez establecida la unidad como bien supremo del Estado, Platón señala también que el tipo de unidad que debe reinar

6 Harto conocido es el isomorfismo entre el Estado y el alma que Sócrates introduce en este diálogo. Pues bien, de manera análoga a como se señala que la unidad constituye un bien indispensable para el Estado, se subraya la necesidad de que la unidad y la armonía imperen en el alma.

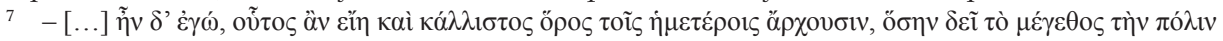

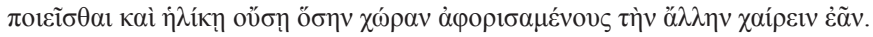

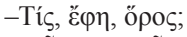

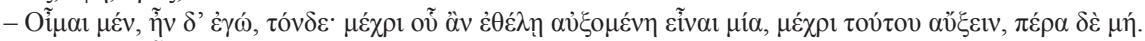

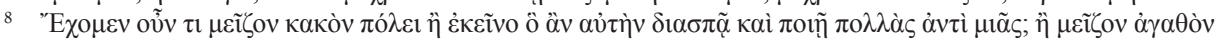

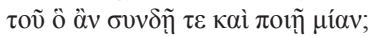

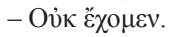


en la sociedad debe cumplir una serie de características que constituyen además la condición de posibilidad para el establecimiento de un Estado justo ${ }^{9}$. El Estado justo es, ya lo hemos visto, un Estado unido. Pero, además, según lo expresado por Sócrates en diversos pasos del diálogo, la unidad del Estado debe ser una unidad de naturaleza racional, autónoma, diferenciada y permanente. La exposición más explícita de todo ello no hace referencia, sin embargo, a la unidad del Estado, sino a la unidad del alma, si bien todo lo dicho a propósito del alma virtuosa cabe aplicarlo igualmente al Estado justo. En efecto, según la exposición de Sócrates, la justicia consiste en primer lugar en que cada uno se ocupe exclusivamente de aquello a lo que por naturaleza le corresponde,

mas no respecto del quehacer exterior de lo suyo, sino respecto del quehacer interno, que es el que verdaderamente concierne a sí mismo y a lo suyo, al no permitir a las especies que hay dentro del alma hacer lo ajeno ni interferir una en las tareas de la otra. Tal hombre ha de disponer bien lo que es suyo propio, en sentido estricto, y se autogobernará, poniéndose en orden a sí mismo con amor y armonizando sus tres especies simplemente como los tres términos de la escala musical: el más bajo, el más alto y el medio. Y si llega a haber otros términos intermedios, los unirá a todos; y se generará así, a partir de la multiplicidad, la unidad absoluta, moderada y armónica. (Rep. IV, 443d-e $)^{10}$

Según lo expuesto por Sócrates, lo que concierne a cada hombre como quehacer propio es su autogobierno mediante la unidad armónica de las distintas partes que componen el alma. Sócrates subraya con fuerza que el logro de esa unidad armónica del alma es un «quehacer interno» del individuo, algo que «concierne a sí mismo", y que se logra adjudicando a cada parte la tarea que le corresponde. Y lo mismo cabe afirmar a propósito de la unidad del Estado. Por el contrario,

9 La defensa de la unidad de la polis como bien supremo tal como es expuesta por Sócrates en la República no es algo evidente para todo el mundo. A lo largo de Política II, 1-6 Aristóteles critica duramente el postulado de Sócrates que afirma que «lo mejor es que toda la ciudad sea lo más unitaria posible», pues, en opinión del Estagirita, la ciudad consiste por naturaleza en una cierta pluralidad, de modo que, si fuera unificándose más y más, finalmente la ciudad quedaría destruida. El examen más certero de las críticas de Aristóteles a la doctrina de la unidad del Estado defendida por Platón se encuentra en el breve ensayo de Proclo titulado «Examen de las objeciones hechas por Aristóteles en el segundo libro de la Política contra la República de Platón», donde el filósofo neoplatónico desmonta las críticas de Aristóteles a la doctrina platónica de la unidad del Estado. El breve ensayo de Proclo está editado por KRoll (1965); hay traducción inglesa con valiosos comentarios y notas en STALLEY (1995).

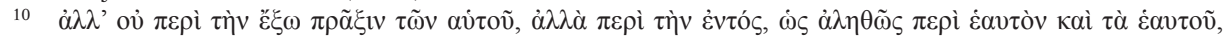

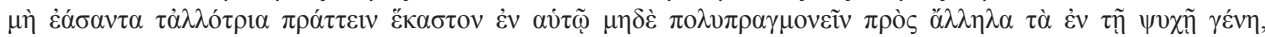

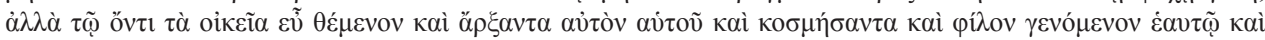

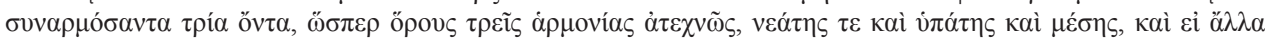

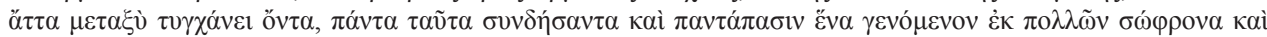

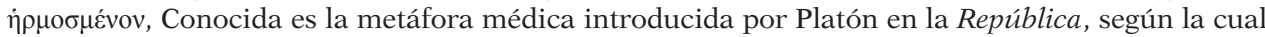
la justicia es la causa de la felicidad en la polis, de manera similar a como la salud es la condición del bienestar del cuerpo. Ambas, justicia y salud, suponen que la multiplicidad de partes que integran el conjunto desarrollen su función propia en favor del conjunto. Adviértase, por otro lado, que Platón acuña un nuevo término, oikeiopragía, para defender una fórmula tradicional en lo relativo a la justicia pública, esto es, «hacer las cosas propias». En efecto, en IV, 434c5-6 leemos oikeiopragía, hekástou toúton tò hautoû práttontos en pólei. Cf. al respecto VeGETTI (1999: 52). 
la injusticia se identifica con la intromisión entre las partes, sean del alma o del Estado $^{11}$. Existen otros pasos del diálogo platónico en que se reivindica la unidad racional y autónoma del alma, equiparable a la naturaleza racional y autónoma del Estado. Así, ya en el libro primero leemos:

...debemos examinar lo siguiente: hay funciones del alma que ninguna otra cosa distinta de ella podría cumplir. Por ejemplo, el prestar atención, el gobernar, el deliberar y todo lo de esa índole: ¿será correcto que atribuyamos estas funciones a otra cosa que al alma y diremos que son propias de ésta? (Rep. I, 353d) ${ }^{12}$

En este fragmento Sócrates subraya la naturaleza autónoma del alma y la idea de que el gobierno de la misma recae sobre la parte que es capaz de "prestar atención», "gobernar» y «deliberar», es decir: sobre la parte racional. En otros lugares, Sócrates señala asimismo la naturaleza diferenciada que debe disfrutar la unidad del Estado:

... no fundaremos un Estado con la mirada puesta en que una sola clase fuera excepcionalmente feliz, sino en que lo fuera al máximo toda la sociedad. Porque pensábamos que en un Estado de tal índole sería donde mejor hallaríamos la justicia. (Rep. IV, 420b) ${ }^{13}$

Y más adelante:

...la dispersión de las tres clases existentes en múltiples tareas y el intercambio de una por la otra es la mayor injuria contra el Estado, y lo más correcto sería considerarlo como la mayor villanía...la injusticia es eso. A la inversa, ... la realización de la propia labor [de cada clase] de modo tal que cada uno haga lo suyo en el Estado...es la justicia, que convierte en justo al Estado. (Rep. IV, 434b-c) ${ }^{14}$

Así pues, tanto la unidad del alma como la unidad del Estado debe partir de la actividad autónoma de su parte racional, que debe dominar sobre las otras, manteniendo cada una en el lugar que le corresponde dentro de la concepción justa del Estado. Expresado de otro modo: el Estado justo se funda en la autonomía de su parte racional y su dominio sobre las demás ${ }^{15}$. El resultado de todo ello será el establecimiento de un Estado justo y duradero.

Frente a este modo de entender la unidad de la polis y la cohesión social, Platón presenta el contramodelo de unidad que parece ofrecer la actividad de los poetas y rapsodas. Podemos afirmar que las características que Platón atribuye a este tipo de unidad constituyen exactamente, una por una, la imagen contraria de las características que visten la unidad lograda mediante la téchne política. Su imagen más

11 Cf. IV, 444b.

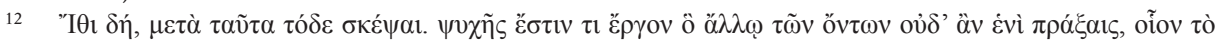

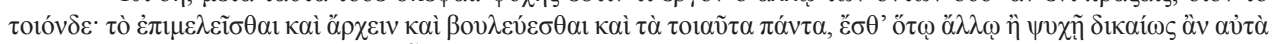

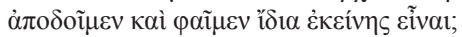

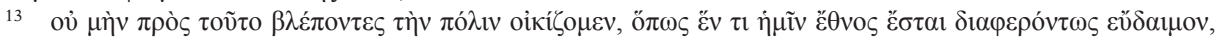

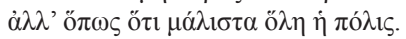

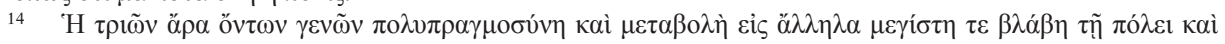

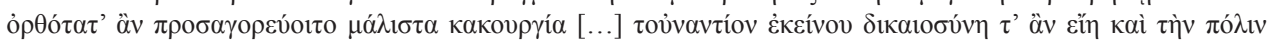

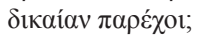

15 Esta misma idea está claramente expuesta mediante el símil del carro alado que elabora Sócrates en la palinodia del Fedro. 
poderosa la encontramos en la metáfora de los anillos imantados, metáfora que no encontramos en ningún otro lugar del corpus platónico, ni tampoco en la obra de ningún otro autor de la antigüedad. Tal como ya se ha adelantado, a lo largo del diálogo Sócrates intenta demostrar que lo que distingue la actividad poética (Ion, Homero) de la actividad filosófica (Sócrates, Platón) es que la segunda constituye un conocimiento y la primera no, pero lo que está en el centro del debate no es solo una cuestión relativa al conocimiento, sino también un problema de naturaleza política. La elección de la metáfora por parte de Platón es ciertamente audaz; en primer lugar, porque el término griego daktýlios (anillo) llama automáticamente la atención del lector o del espectador por su semejanza con el término dáktylos (dactílico), el verso habitual empleado por Homero y otros poetas de la tradición. En segundo lugar, y más fundamental, porque el vínculo al que alude la imagen de los anillos imantados corresponde a un tipo de unidad precaria, precisamente el tipo de unidad que Platón atribuye a la sociedad educada en la poesía tradicional. A juicio de Platón, se trata de una unidad de naturaleza litúrgica, homogeneizadora, irracional y alienada, es decir: una unidad que solo acontece en el momento del espectáculo, desapareciendo una vez que el mismo ha finalizado; una unidad que no toma en consideración las diferencias entre los individuos y entre las clases sociales, sino que entiende la ciudad como una masa informe; una unidad basada en la conexión provocada por las emociones, objeto de la parte más baja del alma, y no por la razón; una unidad, en fin, que no deriva de la voluntad del hombre consciente y autónomo, sino del hombre que se encuentra fuera de sí, poseído por una fuerza externa y falto de una identidad estable ${ }^{16}$. Frente a la frágil unidad de la sociedad basada en las multitudinarias manifestaciones públicas de la poesía, Platón reivindica la unidad real y duradera que proporciona la filosofía y su reducido grupo de expertos. Ya hemos dicho que la metáfora de los anillos imantados es original de Platón; hay que añadir, no obstante, que todo el contenido del monólogo socrático que acompaña y adorna la metáfora está constituido por un gran número de recursos poéticos perfectamente integrados en la tradición y bien conocidos por el ciudadano ateniense. ¿Por qué a juicio de Platón la unidad establecida por poetas y rapsodas es precaria? La respuesta se encuentra en el monólogo socrático del Ion.

\section{La Unidad DEL Estado a tRavÉs de los POETAS y los RAPSODAS}

En primer lugar, la unidad establecida por los poetas y los rapsodas es una unidad de naturaleza irracional, pues no responde a la reflexión sino a la inspiración. El enthousiasmós o inspiración divina es un tema tratado con frecuencia por Platón a lo largo de su obra ${ }^{17}$. Independientemente del contexto en que su tratamiento aparezca, por lo general el enthousiasmós aparece como una capacidad opuesta a la téchne; opuesta, por consiguiente, al conocimiento sistemático que

16 Sócrates compara la inestable identidad del rapsoda con la de Proteo (Ion 541e), dios marino con poderes proféticos cuyo contenido sólo revelaba tras ser atrapado; para evitarlo, Proteo adquiría variadas formas, de modo que su capacidad de metamorfosis era proverbial.

17 Cf. Apología 22a-c, Menón 99c-e, Fedro 245, Leyes 682a, 719c-d e Ion passim. 
posee el technites. Al negarle a Ion la condición de technites y atribuirle en cambio un enthousiasmós de origen divino, Sócrates pretende situar la actividad poética fuera del espacio de la racionalidad. En la metáfora de los anillos la situación de los miembros de la cadena inspirada queda reflejada en la actitud pasiva de los anillos - la piedra magnética es la que atrae y la que transmite el poder de atracción- y por el efecto automático, sin mediación, que asimismo provoca cada miembro de la cadena magnética en sus miembros cercanos. Una metáfora similar será utilizada por Platón en el Fedro, donde Sócrates habla de su amathía, ignorancia, al ligar su discurso a una fuente externa, describiéndose a sí mismo como aggeîon, vasija, queriendo expresar con ello que los discursos que posteriormente vierte los recibe pasivamente y los transmite sin mediación alguna ${ }^{18}$. Pero, además, a lo largo de todo el monólogo Sócrates vuelve una y otra vez sobre la naturaleza irracional del rapsoda inspirado, valiéndose para ello de numerosas referencias culturales: así, Sócrates compara el estado del rapsoda con el de los coribantes, sacerdotes vinculados a la diosa Cibeles que, bajo el efecto de la música, caían junto a sus seguidores en un estado de delirio (Ion 534a, 536c), y con el estado de las bacantes bajo el influjo del dios Dionisos (534a). También relaciona la actividad del rapsoda con la de aquellos que dan oráculos y con la de los profetas $(534 b)^{19}$. Con estas analogías Sócrates da a entender que el poeta es incapaz de dar cuenta de su actividad, porque su estado no está bajo el dominio de la razón. En efecto, la concepción platónica de la inspiración divina se identifica con una suerte de estado de locura que, según nos informa en las Leyes 719c, no hace sino reflejar lo ya descrito por un viejo relato (palaiòs mûthos) de la tradición «según el cual el poeta, cuando se sienta en el trípode de la Musa, no está ya en su juicio (ouk émphron estín), sino que a manera de una fuente deja correr espontáneamente cuanto viene a él», descripción que recuerda el trípode de la Pitia en el santuario de Delfos. Esta descripción del poeta inspirado como un ser irracional es común a todos los comentarios platónicos sobre la inspiración, desde la Apología y el Ion hasta las Leyes ${ }^{20}$. La aportación particular del Ion a lo afirmado en otros diálogos consiste en extender el estado de inspiración del poeta a los rapsodas y a los espectadores que asisten a las representaciones poéticas, detalle fundamental que constituye en gran medida la razón de ser de la metáfora y del propio diálogo. A lo largo del monólogo Sócrates hace hincapié una y otra vez en esta idea, afirmando que los poetas componen "inspirados y poseídos» (éntheoióntes kaì katechómenoi, 533e6-7), "sin estar en su juicio» (ouk émphrones óntes, 534a1-2), «dominados y poseídos por el furor báquico» (barcheúousi kaì katechómenoi, 534a4), "sin estar en su juicio» (émphrones dè oûsai oú, 534a5-6), "poseídos y fuera de juicio» (éntheós te kaì ékphron, 534b5), cuando «la inteligencia ya no está en ellos» (hó voûs mekéti en autôi enêi, 534b5-6), e introduciendo el uso frecuente de un vocabulario que apunta al carácter irracional de su actividad (katechómenos, éntheos, ékphron, enthousiazónton, etc) ${ }^{21}$. La vinculación de la actividad del poeta con la ausencia de razón en esta parte del monólogo también se establece

18 Cf. Fedro 235c-d.

19 Cf. también Apología 22c. En Menón 99c el lugar de los poetas es ocupado por los políticos.

20 Cf. supra nota 12.

21 Con respecto al uso de los términos sinónimos éntheoi y enthousiázontes, el primero se aplica solamente a los poetas y el segundo a los rapsodas y a los espectadores. 
conscientemente mediante recursos literarios muy audaces, como la conexión fonética entre melopoioì (534a1; a6), méle (534a2), méli (534a5) y melirrýton (534b1), de tal modo que la actividad de los poetas líricos queda vinculada a las imágenes de la abeja, la miel y los manantiales de miel. En efecto, la metáfora de la abeja es muy frecuente en la tradición poética griega ${ }^{22}$, y tiene su origen no solo en la similitud que cabe establecer entre los cantos del poeta y la miel, que llega a ser identificada con la poesía ${ }^{23}$, sino también en el ajetreo y en la idea de vuelo que acompañan la actividad de ambos; las imágenes de las alas y el vuelo acercan al poeta a la condición de chamán y resaltan, por consiguiente, su condición irracional. Con todos estos recursos poéticos Sócrates nos está indicando que la cohesión social establecida por poetas y rapsodas en las representaciones poéticas multitudinarias, tan frecuentes en la ciudad ${ }^{24}$, es una cohesión de naturaleza irracional que nada tiene que ver con la unidad del Estado justo ${ }^{25}$.

Por otro lado, Platón no se limita a señalar la naturaleza irracional de la actividad poética, sino también, y de un modo muy insistente, el origen externo de la misma. En su monólogo, Sócrates señala repetidamente el origen divino de la actividad poética. Ya se ha comentado que el poeta es incapaz de dar cuenta de su actividad porque se encuentra en un estado en el que ha perdido la razón; pero es que, además, a su estado se une el hecho de que la inspiración misma es un regalo divino cuya adquisición no depende de la capacidad o de la voluntad del poeta. Por consiguiente, el enthousiasmós no solo supone un estado irracional, sino también un estado de pasividad en el que el poeta queda poseído por una divinidad que habla a través de él. De hecho, en el Ion encontramos el uso de la theía dýnamis (533d3) como noción opuesta a la téchne. En su monólogo central, Sócrates se vale de nociones cercanas como "asignación divina» (theía mô̂ra, 534c1, 535a4), "posesión» (katokoché, 533e7) o «inspiración» (enthousiasmós, 533e5; 535c2; 536b3) para indicar precisamente aquello que no responde a una capacidad interior resultado de

22 Cf. Píndaro, Pítica X, 53-4; Baquílides, fr. X, 9-10; Calímaco, Himno a Apolo 110; EuríPides, Bacantes 142 y 704-11; AristófAnes, Los pájaros 748-50. Sobre las abejas en la literatura griega, cf. WASZinK (1974); SALINAS (2011).

23 La identificación de la miel -y la leche- con la dulzura de la poesía es frecuente en la literatura griega; cf. Ilíada I 247-9; Odisea XII, 187; Teogonía 83-4; PíndAro, Olímpica VI, 21; EsouILo, Euménides 886. Por otro lado, en Píndaro la miel representa frecuentemente la poesía misma; cf. Píndaro, Nemea III, 76-9; XI, 18; Olímpica VII, 7-8; Istmica II, 7-8; VI. Sobre la leche y la miel en la poesía griega, cf. Usener (2012).

24 De esa omnipresencia en la ciudad se queja Jenofonte en Banquete III, 6 y Recuerdos de Sócrates IV, 2, 10, donde los rapsodas son descritos muy despectivamente. Por otro lado, los comentarios del propio Platón en Leyes 659d y en Ion 535d-e y passim nos hacen suponer que los rapsodas gozaban de una enorme popularidad entre la población, independientemente de que las clases más formadas intelectualmente pudieran mirarlos con cierto desprecio. Me inclino a pensar que la razón de la elección de un rapsoda como oponente de Sócrates en el Ion estriba, precisamente, en su enorme presencia social, en su alto reconocimiento popular y en su condición de vínculo necesario en la transmisión de los valores de la tradición.

25 Hay que añadir, no obstante, que es la primera vez en la historia de la literatura griega en que la inspiración divina aparece desvinculada del conocimiento; la primera vez en que la theía dýnamis se entiende como una noción opuesta a la téchne. Hay que recordar que la tradición las considera no sólo compatibles sino necesarias para la actividad poética. Y de hecho, el vocabulario del Ion es el de la tradición, si bien el significado de los términos empleados por Sócrates ya no es el de la tradición, sino que adquiere un nuevo sentido alejado del elogio. 
la autonomía del poeta, sino a una fuerza divina exterior y ajena a él. La referencia a los coribantes, a las bacantes, a los que dan oráculos y a los profetas ya nos transmite la imagen de la dependencia de una divinidad externa. Y todo ello queda perfectamente ilustrado en la imagen de la piedra imantada que no solo atrae, sino que también transmite su fuerza a los anillos. Platón se sirve además de otras analogías y figuras poéticas. Así, según la explicación de Sócrates, el «buen decir» del rapsoda, su capacidad para hablar sobre Homero, es la consecuencia de una potencia divina (theía dýnamis, 533d3) y la «mayor» (mégiston, 534d5) y «evidente» (enargès, 535c4) prueba (tekmérion) de ello lo constituye el carácter intermitente de la inspiración, tal como lo pone de manifiesto el caso del poeta Tínico de Calcis ${ }^{26}$, un poeta muy mediocre que, sin embargo, fue capaz de componer un peán muy hermoso y muy reconocido al dios Apolo cuando fue inspirado por su Musa, lo que demuestra que los bellos poemas (tà kalà...poiémata, 534e3) no son humanos y pertenecientes a los hombres (ouk anthrópiná...oude anthrópon, 534e2-3), sino divinos y pertenecientes a los dioses (allà theîa kaì theôn, 534e3-4), es decir: ajenos al poeta. Por otro lado, como prueba del origen externo de la capacidad poética Sócrates señala también el carácter selectivo del «buen decir» de poetas y rapsodas, algo que se manifiesta en el hecho de que a cada poeta le corresponde un tipo particular de composición, y a cada rapsoda le corresponde un determinado poeta. A este respecto, es significativo el uso repetido de los verbos artáo (533e2), anartáo (533e3) y exartáo (533e5) — pender, estar suspendido-, para transmitir la idea de dependencia y falta de autonomía. Estos hechos ponen de manifiesto nuevamente que la actividad poética no responde a la posesión de una téchne, pues en ese caso sería satisfecho el principio de la totalidad que rige la posesión de cualquier téchne, sino que a cada rapsoda le corresponde un poeta, y a cada poeta una divinidad. La analogía socrática de la piedra magnética y los anillos imantados expresa la idea de que el buen poeta y el buen rapsoda no son sino meros instrumentos pasivos de la potencia divina, y en ese sentido, seres alienados poseídos por una fuerza ajena. Dicho de otro modo: el poeta no es un ser autónomo. En este sentido, hay que señalar, finalmente, que la vinculación de la actividad del poeta a una fuerza ajena a él también se establece en el monólogo mediante el uso de ciertos recursos poéticos: así, la miel y la leche son los alimentos transformados por las bacantes a partir de las aguas de los ríos ${ }^{27}$, y el poeta toma sus cantos de los manantiales ${ }^{28}$ y de los jardines y valles de las Musas ${ }^{29}$, imágenes que expresan la fuente externa de su inspiración. También es muy conocida la descripción socrática del poeta como «una cosa alada, ligera y sagrada», imagen que remite a un ser íntimamente vinculado a la divinidad (y en ese sentido, sagrado, hierón), capaz de ser poseído por ella (koûphon, traducido por «ligero», también significa «vacío» $\left.{ }^{30}\right)$ y, en consecuencia, capaz de componer mediante una intensa actividad. Sócrates incide repetidamente en la relación de absoluta dependencia de los poetas con respecto a la divinidad; así, según su

\footnotetext{
26 La única referencia del poeta además del Ion se encuentra en Porfirio, Abstinentia II 18.

27 Cf. EuríPIDEs, Bacantes 690-ss.

28 Cf. Píndaro, Olímpica VI, 85-6; Istmica VI, 74-5; Lucrecio, De rerum natura IV, 2-3.

29 Cf. Píndaro, Olímpica IX, 26-7; cf. tb. Leyes VI, 761b; Aristófanes, Las ranas 1300.

30 Cf. Platón, Timeo 91d.
} 
descripción, la divinidad los utiliza como servidores (chrêtai hypéretais, 534c8) ${ }^{31}$, a fin de que nosotros, los que les escuchamos (hemeîs hoi akoúontes, 534d1-2), es decir, los espectadores, último eslabón de la cadena magnética, sepamos que no son ellos los que dicen cosas tan excelentes, sino que es la divinidad misma la que se dirige a nosotros (phthéggetai pròs hemâs, 534d4) a través de ellos (dià toúton, $534 \mathrm{~d} 4)^{32}$. Todo este despliegue de ejemplos y recursos poéticos está dirigido, por consiguiente, a reforzar la idea de que la cohesión social establecida por poetas y rapsodas es una cohesión de naturaleza heterónoma, alienada, idea que queda bien reflejada en la metáfora de los anillos imantados.

En su extenso monólogo, Sócrates se centra principalmente en describir el estado alienado del poeta y el contexto de irracionalidad en que la actividad poética se desenvuelve, así como el origen externo, heterónomo, ajeno al poeta y al rapsoda, de la fuerza que lo posee. Sócrates no se limita a ello, sino que mediante el uso de ciertos recursos literarios, le indica al lector que las consecuencias de la naturaleza irracional y heterónoma de la actividad poética conlleva el hecho de que la cohesión social establecida mediante la celebración de los frecuentes y multitudinarios festivales poéticos es una cohesión de naturaleza homogeneizadora y meramente litúrgica. Una unidad, por consiguiente, que no respeta las diferencias entre clases y ciudadanos, y que tampoco satisface el objetivo de lograr una unidad permanente. Aunque estas dos últimas notas no están desarrolladas de modo explícito en el monólogo socrático, sí que nos da claras pistas al respecto. En primer lugar, la imagen misma de los anillos imantados produce la imagen y la sensación de homogeneidad entre todos aquellos que toman parte en la representación poética, desde el poeta y el rapsoda hasta los propios espectadores, vinculados todos ellos al poder de la Musa $^{33}$. Efectivamente, en esa imagen la única figura que aparece individualizada con respecto al conjunto es la piedra imantada, que representa a la Musa. Todos

31 Sócrates emplea en esta ocasión el término fuerte hyperétes en lugar del clásico therápon. El poeta como sirviente de las Musas es habitual en la literatura griega (Mousôn therápon). Cf. Hesíodo, Teogonía 100; Teognis, fr I, 769; Aristófanes, Los pájaros 900, 913.

32 A estas alturas del diálogo, se manifiesta claramente que los términos hermeneús y hermenéuein, intérprete e interpretar, son entendidos de modo muy diferente por Ion y por Sócrates, de modo que, si para Ion la interpretación del rapsoda supone un papel activo, para Sócrates el rapsoda juega un papel pasivo de mero transmisor de lo expresado por la divinidad. En el transcurso del diálogo puede comprobarse que la estrategia de Sócrates consiste en aceptar en un principio que Ion conoce el texto homérico para, posteriormente, hacerle comprender que en realidad carece de todo conocimiento, y que su condición de hermeneús responde simplemente a la de mediador inspirado por la divinidad, y no a la de intérprete poseedor de una téchne. Por su parte, el uso que del término hermeneús hace el rapsoda indica claramente que no se refiere simplemente a la condición de mediador del poeta, sino también a la de intérprete, lo que implica la comprensión del texto homérico; a este respecto, el término diánoia aparece en Ion 530c1, 530c4 significando el pensamiento del poeta como algo opuesto a los versos o las palabras, tà épe (de un similar a como Aristóteles distingue en Poética 1449b-1450b diánoia y léxis); por otro lado, la expresión tà legóme$n a$, identificada en este contexto con he diánoia, aparece como objeto del verbo de conocimiento syneînai, mientras que hóti légei ho poietès, también identificada con he diánoia, aparece como objeto del verbo de conocimiento gignóskein. A lo largo de su intervención, Sócrates busca romper el vínculo que une la rapsodia con el conocimiento.

33 Además de una línea de inspiración vertical, en las representaciones poéticas también se da una línea horizontal, en la que participan «cantantes y danzantes del coro, instructores y ayudantes de instructores» (choreutôn te kaì didaskálon kaì hypodidaskálon, 536a4-5). 
los demás individuos que participan en la representación poética están representados mediante anillos cuya única diferencia entre ellos es la cercanía de la fuente original. En ese sentido, nada distingue al poeta del espectador o del instructor. La naturaleza indiferenciada de los miembros de la cadena de inspirados se refleja en la propia sintaxis, pues cuando Platón la describe se sirve de una compleja expresión dià dè tôn enthéon toúton állon enthousiazónton (533e4-5), que transmite la sensación de una ruptura entre las líneas de separación de los distintos elementos que toman parte en la cadena. Esta imagen es exactamente la imagen contraria de lo que a juicio de Platón debe ser la unidad de la polis, una unidad, como sabemos, fundada sobre las diferencias en la naturaleza de cada ciudadano y clase social, y en la que debe regir la oikeiopragía. Por otro lado, la sensación de homogeneidad que transmite la metáfora de los anillos parece ir unida a la idea de multitud; en este sentido, es llamativa la referencia en el diálogo al alto número de espectadores presentes en las manifestaciones poéticas: en el diálogo Sócrates habla de la presencia de «veinte mil personas» (cf. 535d) escuchando al rapsoda. Resultar vencedor en las Panateneas o en Epidauro suponía sin duda un gran reconocimiento social para los rapsodas; pero se trata de un reconocimiento que, en todo caso, no afecta lo más mínimo en la opinión de Sócrates, quien jamás consideró el número de seguidores como criterio de excelencia ${ }^{34}$. Y de hecho, en la obra de Platón y de Jenofonte, Sócrates nunca aparece dirigiéndose a la multitud, sino al pequeño grupo de reunión o banquete, lo que cabría entender como una crítica a la representación pública de la poesía épica desde el punto de vista superior representado por las celebraciones de los reducidos grupo de origen aristocrático ${ }^{35}$. Finalmente, como consecuencia de su naturaleza irracional, heterónoma y homogeneizadora, la unidad lograda por los poetas y rapsodas en las multitudinarias manifestaciones poéticas no es una unidad permanente, sino una unidad puramente litúrgica que finaliza cuando finaliza el espectáculo, del mismo modo que la cohesión entre los anillos se da mientras la piedra magnética está presente, pero una vez que su efecto desaparece, desaparece también su unidad. No podría ser de otro modo, habida cuenta de que la actividad de poetas y rapsodas no es el resultado de un conocimiento real, sino de una asignación divina que tiene un origen externo y sobre el que no se tiene control alguno. El mensaje de Platón es claro: ajena a los principios que rigen el verdadero conocimiento, la actividad de poetas y rapsodas responde a la inspiración, regalo de los dioses que, al tiempo que los convierte en seres divinos, los convierte también en seres ignorantes, y en cuanto ignorantes, incapacitados para la construcción de un Estado justo, que en una sociedad regida racionalmente debe corresponder a los filósofos ${ }^{36}$.

34 El desprecio por la multitud es habitual en el Sócrates platónico: cf. Hipias Mayor 286c; Laques 201c; Critón 43d; Fedón 69d, 80d; Leyes 632e, 688e.

35 Sobre esta cuestión, cf. Collins (2004: 138-142).

36 Que es la misma conclusión a la que se llega en el Fedro con respecto a la unidad del alma: sólo cuando la parte racional gobierna el alma existe la garantía de una unión justa, estable y duradera. 


\section{BibliografÍA}

\section{Fuentes:}

Dielh, E. (1954). Anthologya lyrica graeca. Lipsiae [1936].

García Gual, C. (ed.) (1999). Homero. Ilíada. Odisea. Texto griego y traducción. Traducciones de Emilio Crespo Güemes y José Manuel Pabón, Apéndice: Óscar Martínez. Madrid: Espasa Calpe, Biblioteca de Literatura Universal.

Lamb, W. R. M. (2016). Plato. Complete works, vol. I: Euthyphro, Apology, Crito, Phaedo, Phaedrus and vol. VIII: Statesman, Philebus, Ion. Cambridge: Loeb Classical Library [1925].

Lanata, G. (1963). Poetica Pre-platonica. Testimonianze e Frammenti. Firenze. La Nuova Italia. Meridier, E. (1978). Platon. Oeuvres Complètes. Paris: Les belles lettres [1931].

Rodríguez Adrados, F. (2010). Líricos griegos: elegíacos y yambógrafos arcaicos (siglos VII-V a. C.) (2 vol.). Madrid: CSIC.

Literatura secundaria:

Aguirre, J. (2013). Platón y la poesía. Ion. Madrid: Plaza y Valdés.

Bremer, J. (2005). Plato's Ion. Philosophy as performance. North Richland Hills: Bibal Press.

Capuccino, C. (2005). Filosofi e Rapsodi. Testo, traduzione e commento dello Ione platonico. Bologna: CLUEB.

Collins, D. (2004). Master of the Game. Competition and Performance in Greek Poetry. Cambridge: Cambridge University Press.

Kroll, W. (1965). Procli Diadochi in Platonis rem publicam commentarii, 2 vol. Leipzig: Teubner [1899-1901].

Salinas, H. (2011). El modelo de la abeja obrera en la época clásica. Tesis Doctoral. Universidad de Barcelona.

Pradeau, J.-F. (2001). Platon. Ion, suivi de Édouard Mehl. Deux lectures de l'Ion. M. Ficin et J. W. Goethe et Jean-Luc Nancy. Le partage des voix. Paris: Ellipses.

Rijksbaron, A. (Ed.) (2007). Plato. Ion. Or. On the Iliad. Edited with Introduction and Commentary. Leiden-Boston: Brill.

Stalley, R. F. (1995). «The Unity of the State: Plato, Aristotle, and Proclus», en:Polis 14, pp.129-149. DOI: 10.1163/20512996-90000478

Usener, H. (2012). "Milch und Honig», Kleine Schriften. Vol. 4: Arbeiten zur Religionsgeschichte, pp. 398-417 [1902]. DOI: https://doi.org/10.1017/CBO9780511698507.018

Vegetti, M. (1999). Guida alla lettura della Repubblica di Platone. Roma-Bari: Laterza.

Waszink, J. H. (1974). Biene und Honig als Symbol des Dichters und der Dichtung in der griechisch-römischen Antique. Opladen.

Universidad del País Vasco

JAVIER AGUIRRE

Facultad de Educación, Filosofía y Antropología

Departamento de Filosofía

Avenida de Tolosa 70

20018 Donostia-San Sebastián

javier.aguirre@ehu.eus

[Artículo aprobado para publicación en diciembre de 2017] 